\title{
Worry about eldercare in China: The role of family relations, socio-economic resources, and community services in 2000 and 2010
}

\author{
Rongjun Sun ${ }^{1}$, Haitao Wang ${ }^{2 *}$ \\ ${ }^{1}$ Department of Anthropology, Criminology and Sociology, Cleveland State University, \\ Cleveland, Ohio, United States \\ ${ }^{2}$ China Research Center on Aging, Beijing, China
}

\section{ARTICLE INFO}

Received: February 22, 2019

Accepted: April 16, 2019

Published: April 27, 2019

${ }^{*}$ CORRESPONDING AUTHOR

Haitao Wang,

China Research Center on

Aging, Beijing, China.

haitao_wang@crca.cn

\section{CITATION}

Sun R, Wang H (2019) Worry about eldercare in China: The role of family relations, socio-economic resources, and community services in 2000 and 2010. International Journal of Population Studies, 5(2):1-13.

doi: $10.18063 / i j p s . v 5 i 2.1046$

Copyright: () 2019

Sun $\mathrm{R}$, Wang $\mathrm{H}$. This is an Open-Access article distributed under the terms of the Creative Commons Attribution-Non Commercial 4.0 International License (http://creativecommons.org/ licenses/by-nc/4.0/), permitting all noncommercial use, distribution, and reproduction in any medium, provided the original work is properly cited.

\begin{abstract}
Using the survey on aged population in urban/rural China from 2000 and 2010, we aim to achieve the following three objectives: First, to document the general trend in older adults' worry about eldercare, their family relations, socio-economic resources, and the availability of community services; second, to assess if improving socio-economic resources and availability of community services reduce older adults' worry about eldercare; and third, to examine if family relations are still important during such social changes. Results show that older adults' improving socioeconomic conditions and expanding community services are associated with less worry about eldercare. Meanwhile, family relations, measured by the number of children, living arrangements, and children's filial piety, remain important. Our findings demonstrate that while building social welfare programs, including providing community services, certainly alleviates older adults' worry about eldercare; they are no substitute for family ties, which should be facilitated rather than overlooked by public policies.
\end{abstract}

Keywords: China; Eldercare; Family; Social services

\section{Introduction}

\subsection{Research Questions}

Provision of eldercare, which includes financial or material assistance, personal care, and emotional support to older adults (Chen, 2002; Knodel, 2012), has become a contested issue in China, as the country has undergone dramatic demographic changes in the past decades. On the one hand, with unprecedented fertility decline, there are fewer children per family, meaning fewer family caregivers to elderly parents when needs arise. In addition, more Chinese older adults live alone, separately from their adult children (Hu and Peng, 2015; Zeng and Wang, 2003). These trends may prompt older adults' worry about receiving care in old ages. On the other hand, the recent development of the welfare state in China seems to alleviate such a concern and to make independent living an increasingly viable option ( $\mathrm{Du}, 2013)$. More older adults have benefited from expanding social programs that provide income or medical care coverage. Community services to older adults have been growing and playing a more important role in eldercare in China (Zhang, Yeager, and Hou, 2016). Against such a backdrop, this paper uses the survey on aged population in urban/rural China from 2000 and 2010 to explore the following three research questions: (1) What is the general trend in older adults' characteristics in their family relations, socio-economic resources, availability of community services, and their worry about eldercare in the first 
decade of the $21^{\text {st }}$ Century? (2) Do the improving socio-economic resources and availability of community services play a positive role in reducing older adults' worry about eldercare? and (3) In such a backdrop, is the role of family relations still important in older adults' worry about eldercare?

\subsection{Population Aging and Changes in Family Structure in China}

Population aging in China results from both low fertility rate and rising life expectancy. The one-child policy in the past few decades since 1979 has contributed to a declining portion of the young in the general population. Meanwhile, rising life expectancy allows more people to live to old ages. There are currently more than 200 million older adults in China aged 60 or older, more than 20 million of whom were oldest old, or over the age of 80. In 2019, one in 11 people worldwide was aged 65 or over. It is projected to grow to one in six by 2050, and at the same time, the number of those aged 80 or above will reach 426 million (United Nations, 2019). In the past few decades, China's fertility rate has been on a downward track. It has started declining since the 1960s, when total fertility rate was around 6.0. It had dropped from 5.8 in 1970 to 2.8 in 1979 before the implementation of the one-child policy (Jiang and Liu, 2016). With the one-child policy in full swing, fertility fell below replacement in the early 1990s and was around 1.5 by 2010 (Cai, 2013). As a result, the average number of children per family is lower and the average size of the family is shrinking. The average number of family members declined from 3.96 in 1990, to 3.46 in 2000, and to 3.09 in 2010 (Hu and Peng, 2015).

Meanwhile, decades of social and demographic changes have gradually eroded the traditional ideal of having multiple generations living under the same roof. More Chinese older adults are increasingly living alone or with a spouse only. Using Chinese Census data, Hu and Peng (2015) documented that the percentage of parents living with married or unmarried children in two- or three-generation households has steadily declined from $74.2 \%$ in 1990 to $65.3 \%$ in 2000 and $53.0 \%$ in 2010 . They found $40 \%$ of older adults living in empty-nested households, i.e. living alone or with spouse only. Such a change can be attributed to the growing number of one-child families that makes the multi-generation living arrangement demographically difficult, and rising incomes for both the young and old and housing availability that make living independently possible (Du, 2013; Meng and Luo, 2008).

\subsection{Expanding Older Adults Welfare Programs}

As population aging places an ever-growing constraint on family's ability to provide eldercare, the state has launched a series of social programs to address such a challenge. The National Committee on Aging was established in 1999, and the state has made substantial progress in establishing a social safety net for the elderly population (Feng et al., 2012). In 1997, the State Council passed a decree to set up a uniform old age security system for urban employees, who contribute to their personal account, which is managed by the local government. By the end of 2012, 304 million urban employees had participated in this program. Monthly benefit for the pensioners has been on the rise in the past decade (Zhang, 2017). In rural areas, China initiated the New Rural Pension Program (NRPP) in 2009, aiming at covering all the rural older adults. The new program is funded by contributions from individuals and subsidies from local and central governments. By the end of 2011, about 200 million rural residents had participated in the program ( $\mathrm{Du}, 2013$ ). In addition, the minimum security program is set up for those with low or no income. It had provided coverage for 74 million urban/rural residents by 2012, among whom 3.4 million were older adults in the cities and 20.2 million older adults in rural areas, which accounted for $15.7 \%$ and $37.8 \%$ of older adult population, respectively (Yang, 2013).

China's network of medical care currently covered both urban and rural areas, with more than 1.3 billion beneficiaries (Wu and Luo, 2013). While urban residents are covered by the Urban Employee Basic Medical Insurance (UEBMI), which provides insurance to urban employees and retirees, and Urban Resident Basic Medical Insurance (URBMI), which covers self-employees, employees in informal sectors, and the unemployed. Rural residents are covered by the New Cooperative Medical Scheme (NCMS). Under this coverage, part of the patient's medical expenses is reimbursed. The treatment for some major diseases, such as lung cancer and stomach cancer, is covered by up to $90 \%$. The personal share of all medical expenses had gone down from 58\% in 2002 to 35\% in 2011 (Wu and Luo, 2013).

Meanwhile, the state steps into promoting community-based services aiming to supplement family care and help older adults remaining in the community (Xu and Chou, 2011). These services, both formal and informal supports available to older adults within the community provided by people other than family members (Shen and Yeatts, 2013), include household chores, health care at home, and meal services ( $\mathrm{Du}, 2013)$. Various pilot projects and experiments have been conducted in both urban and rural areas since the 1990s (Lee and Kwok, 2006), from government-operated services to private enterprises. While some of the services are wholly funded or partially subsidized by the local government, some are paid out of pocket by individual customers (Lin, 2017). 


\subsection{Worry about Eldercare and Hypotheses}

\subsubsection{The impact of economic resources and community services}

As reviewed earlier, the traditional practice of having adult children taking care of older adults has been under pressure from drastic demographic changes in the past decades in China. As both the number of children and the proportion of older adults coresidence with adult children are declining, it is becoming more infeasible to totally rely on families to provide eldercare. In light of these challenges, the state has increased investment in welfare programs to provide older adults with more resources in income and health-care coverage, which have started to show effect. For example, health insurance programs in urban and rural areas, mainly UEBMI, URBMI, and NCMS, have been found to be effective in booting health-care utilization, although rural area coverage is less generous (Zhang, Nikoloski, and Mossialos, 2017).

With expanding public pension and other welfare programs, older adults, especially those in urban areas, have more disposable income and become less dependent on others financially. Even for those living in rural areas covered by NRSP, which offers lower benefits than in urban areas, the benefit level has doubled between 2009 and 2013. The NRSP coverage is expanding rapidly with increasing government subsidies. Several studies have shown that pension from NRSP to rural residents has improved their sense of personal security, self-esteem, and ability to support themselves. Meanwhile, it reduced their worries about later life (Liu et al., 2015). The expanding health-care coverage makes medical treatment more affordable and accessible. Furthermore, the increasing availability of community services provides older adults with alternative options in seeking care. More older adults turn to affordable and responsive community services for help instead of relying on children (Leung, 2010). Such a trend has been observed in some other Asian societies. In Japan, which shares Eastern Asian traditional culture, there has been a shift from family care to socialization of care. Eldercare responsibilities have gradually been transferred from the family to the state (Hayashi, 2011). It has been reported that as pension programs were implemented in Taiwan, there was a substantial decline in older adults relying on private monetary transfers (Chan et al., 2003). A study in Thailand found that the financially better-off older adults were more likely to pay non-relatives for caregiving than those less wealthy (Knodel and Chayovan, 2012). By the same token, older adults with less power and fewer resources in Hong Kong showed a stronger expectation to be taken care of by their children because of limited choice (Ng, Phillips, and Lee, 2002). Similarly, in Spain, characterized by a high proportion of multigenerational households in Europe, it is the disadvantaged older adults with lower educational or financial status who are more inclined to coreside with relatives (Fernandez-Carro, 2016). Knodel (2012) predicted that with the expansion of state welfare allowance programs, such as pensions and social security type of benefits, there would be a reduction in reliance on children for eldercare, and an increase in the use of formal services to substitute for it.

It seems that expanding welfare programs and community services provide older adults with an alternative and viable option of receiving care. Therefore, we hypothesize that older adults' socio-economic resources, mainly their income and health-care coverage, and the availability of community services will make them less worry about eldercare (Hypothesis 1).

\subsubsection{Does the family still matter?}

As older adults have more resources at their disposal and have more access to community services, an interesting and important question emerges: Is the family still relevant, or at least becoming less important? The picture is not as clear as evaluating the impact of the resource factors discussed above.

On the one hand, Cowgill and Holmes (1972) claimed that, in the process of modernization, one traditional function of the family of supporting its older members might fade away as a social welfare state gradually took its place. Older adults' increasing resources from outside the family, largely due to the establishment of public welfare programs, may make them less dependent on the family networks for support, such as seeking medical treatment and eldercare. Typical aspects of family structure, such as number of children and whether living with adult children, may become less critical. A comparative study of four Asian societies found that family size was not particularly important in determining the care older adults received when there was a remarkable decline in fertility. What mattered was children's character rather than the number (Asis et al., 1995). Living separately from children may not necessarily imply older adults being abandoned or an erosion of traditional family values. The practice of multi-generational coresidence might be partly attributed to housing shortage in the past (Zavoretti, 2006). Living in separate residence has been reported to be preferred by some aging parents and their children in China. Although living apart, parents and married children maintain frequent contact and offer support to each other (Whyte, 2003). As Taiwan experienced industrialization and growth in income before the end of the last century, many older adults expressed interest in independent living that provides privacy and freedom (Lee, Lin, and Chang, 1995). A similar trend was observed among Chinese older adults in Singapore (Mehta, Osman, 
and Alexander, 1995). Living arrangements have become a result of each generation's needs, economic resources, health, and ability to provide (Asis, Domingo, Knodel et al., 1995). While coresidence with children was found to be beneficial to the psychological well-being of the widowed Chinese older adults, it did not make any difference for those who were married (Wang, Chen, and Han, 2014). Another study found that the daily maintenance dimension of filial piety, which includes the frequency of contact and assistance with daily activities, was not associated with life satisfaction or psychological well-being of Chinese older adults (Cheng and Chan, 2006). Following these findings, we hypothesize that the association of family relations, measured by the number of children, coresidence with at least one adult child, and children's filial piety, with older adults' worry about eldercare may become less significant from 2000 to 2010, when older adults' socio-economic resources and the availability of community services are taken into account (Hypothesis 2a).

On the other hand, it was found that even with dramatic economic development in recent decades, family-based care is still the backbone of care provision for older adults in China (Shen and Yeatts, 2013; Zavoretti, 2006). Families have been the bedrock of providing care to older adults in China and many Asian societies. The Confucian value of filial piety, where the younger generation is expected to respect and take care of their elderly parents, has been instilled for generations (Chow, 2004; Zhang and Yeung, 2012). "More children, more happiness" has been the conventional wisdom. Living with at least one married son has been the ideal living arrangement. Even though NRSP has improved the quality of life for many Chinese older adults in rural areas, the impact of family structure, such as the number of children, remains significant (Liu, Han, Xiao et al., 2015). Thus, the crucial role played by families, especially adult children, may not simply fade away as alternative options of care are available for at least two underlying reasons.

First, children are thought to provide better care than nonfamily caregivers. They know better the needs and habits of older adults, thus able to provide better care (Chen, 2002). In one study in Hong Kong, Chinese older adults gave a detailed account of the advantages of living with adult children (Ng, Phillips, and Lee, 2002). Living with children provided a sense of security. They felt happy and safe. They could count on getting help immediately once an emergency came up. Children gave the best emotional support.

The second reason may be tied to the strong value and practice of filial piety, which has been instilled in the collective consciousness. Adult children's provision of care for their parents does not only serve a practical function - meeting parents' material or other needs but it is also a manifestation of filial piety and moral obligation on the part of children. It is a symbol of adult children's appreciation and repayment of care and love received early in life from parents (Asis, Domingo, Knodel et al., 1995). The absence of such an act makes both parents and children "lose face," even though parents' needs may be met by other sources, such as paid workers or institutions. One qualitative study in Thailand is a case in point. Even though coresidence with children has declined, $80 \%$ of the respondents from a national survey in 2011 still regarded it as the most appropriate living arrangement, regardless of the respondent's age. About two-thirds of the respondents agreed that children should be the main provider of care for older adults. Children were viewed as the ideal personal care providers. Concern about having an outside person to fulfill such an intimate role was still common. While paid caregivers were acceptable when children were working or serving as children's assistant, full-time services that replaced care from children were viewed less favorably. As one respondent said, "No matter who will be caregiver they are not children," followed by another, "I don't think a paid caregiver can substitute for children for giving care to parents" (Knodel, 2012, p. 20). In Japan, family-based care is still central to eldercare in spite of the introduction of long-term care insurance scheme in 2000 (Kawakami and Son, 2015). Even in Spain, there is a strong intergenerational solidarity. Informal support provided by family members is pre-eminent in its culture. Taking care of older adults by younger generations is an expected duty rather than an option (Fernandez-Carro, 2016). Therefore, we develop an alternative hypothesis to Hypothesis 2a: The association of family relations with older adults' worry about eldercare remains significant in both years even when older adults' socioeconomic resources and the availability of community services are taken into account (Hypothesis 2b).

\section{Data and Methods}

\subsection{Study Population}

We will use the survey on aged population in urban/rural China to describe the general trend of eldercare in China and test the research hypotheses. The survey is conducted by China Research Center on Aging, which is a consulting branch of China National Committee on Aging. All survey procedures meet the ethical standard of the committee. So far, four waves of data have been collected in 2000, 2006, 2010, and 2016, respectively, whereas the data from the most recent wave are currently unavailable. The survey covers all geographical regions: North, Northeast, East, Southcentral, 
Southwest, and Northwest. Out of 31 provinces and national metropolises, 20 are selected. The survey follows a stratified, multistage sampling design to randomly interview those 60 -year-old or older. This analysis is based on data from two waves in 2000 to 2010 .

\subsection{Measurement of Worry about Eldercare}

Worry about eldercare is measured by older adults' response to the question of whether they are worried about getting care when needed. There are five response options: (1) Not worried at all; (2) almost not worried; (3) so-so; (4) a little worried; and (5) very worried. It is recoded into two categories: Either worried (4 or 5) or not worried (1,2, and 3).

\subsection{Covariates}

Family relations are measured by the number of children, living arrangements, and older adults' perception of their children being filial or not. The living arrangements have three categories: Living alone or with spouse only, living with children, and living with others. As a subjective measure to gauge family relations, older adults were asked in the survey about whether they had any worry about children being unfilial, which is coded as yes or no.

Older adults' socio-economic resources mainly refer to income and medical coverage, including both objective and subjective measures. Two objective measures are whether an older adult receiving any income from public sources (yes or no), including pension from state insurance programs or enterprises, security income for the poor, and any income from other public sources; and whether an older adult receiving any public medical care coverage coded as yes or no. Two subjective measures include whether an older adult having any worry about insufficient income or unaffordable medical care, coded as yes or no.

There are questions about eight kinds of community services asked in both years: Household work, personal care, doctors' home visits, companionship (having someone to chat), older adults' hotline, meals to home, as company to see a doctor or to go shopping. For each service, older adults were asked about the availability in the community, their need, and their use of the service. Since the availability and need for the last four types of services are low in both years (under $10 \%$ for all in 2000), we will only include the first four types of services in the analysis. Preliminary results indicate that the sheer availability of these services is not significant. Instead, we construct an unmet need variable for each service: If there is a need for a specific service but unavailable in the community, it is coded as yes, otherwise no.

Among the control variables, there are age, sex (male, female), and residence (urban and rural). Since the percentage of being divorced or never married is $<2 \%$, marital status is coded as a dummy variable: Currently married or not. Education is coded at three levels: Illiterate, elementary school, and middle school or higher. An older adult's health status is measured by their difficulty in performing an array of activities of daily living (ADL), which include six basic activities: Eating, clothing, toileting, getting in/out of bed, bathing, and walking. Each activity is measured by a score at three levels: No difficulty, a little difficulty, and unable to perform. Since more than $70 \%$ of older adults from both years reported no difficulty in any of the six activities, we recode it into a binary variable: Having any ADL difficulty or no difficulty at all. Home ownership is a dummy variable: Yes or no.

\subsection{Analytical Strategies}

In the following analysis, we will first present descriptive statistics to illustrate the changes in older adult population between 2000 and 2010. Next, we will adopt three logistic regression models for each year to test the two hypotheses. Model 1 will only include family relations variables in addition to the control variables to show the effect of family relations without socioeconomic resource variables. Socio-economic resource variables will be added to Model 2, which will partially test Hypothesis 1 , and Hypothesis $2 \mathrm{a}$ and $\mathrm{b}$. Community service variables will be added to Model 3 to completely test all hypotheses.

\section{Results}

\subsection{Description of Older Adults in 2000 and 2010}

Table 1 presents descriptive statistics of the two elderly samples in 2000 and 2010, respectively. Although the dependent variable - worry about eldercare - remained virtually the same between 2000 and 2010, family relations, older adults' socio-economic resources, and unmet need for community services had undergone dramatic changes during the same time period. 
Table 1. Socio-demographic characteristics of the surveyed older adults in 2000 and 2010.

\begin{tabular}{|c|c|c|}
\hline Variable & 2000 & 2010 \\
\hline Worry about eldercare (\%) & 39.8 & 38.7 \\
\hline Age & $69.1(6.8)^{\mathrm{a}}$ & $72.2(7.4)^{\mathrm{a}}$ \\
\hline \multicolumn{3}{|l|}{$\operatorname{Sex}(\%)$} \\
\hline Male & 53.0 & 51.7 \\
\hline Female & 47.0 & 48.3 \\
\hline \multicolumn{3}{|l|}{ Residence (\%) } \\
\hline Urban & 50.2 & 50.2 \\
\hline Rural & 49.8 & 49.8 \\
\hline \multicolumn{3}{|l|}{ Marital status (\%) } \\
\hline Currently married & 62.6 & 65.8 \\
\hline Currently not married & 37.4 & 34.2 \\
\hline \multicolumn{3}{|l|}{ Education (\%) } \\
\hline Illiterate & 43.1 & 29.0 \\
\hline Elementary & 34.3 & 38.9 \\
\hline Middle and high school & 22.6 & 32.1 \\
\hline Number of children & $4.0(1.8)^{\mathrm{a}}$ & $3.2(1.6)^{\mathrm{a}}$ \\
\hline \multicolumn{3}{|l|}{ Living arrangements $(\%)$} \\
\hline Alone or with spouse only & 38.4 & 53.8 \\
\hline With children & 55.5 & 40.4 \\
\hline Other & 6.1 & 5.8 \\
\hline No worry about children's filiality & 68.8 & 75.8 \\
\hline ADL difficulty & 18.7 & 25.8 \\
\hline Home ownership & 53.1 & 72.5 \\
\hline Receiving any public income & 50.6 & 73.7 \\
\hline Receiving medical care coverage & 63.3 & 95.7 \\
\hline No worry about income & 56.2 & 61.4 \\
\hline No worry about medical care & 46.8 & 49.9 \\
\hline Unmet need for housework work & 11.2 & 16.9 \\
\hline Unmet need for personal care & 13.1 & 25.0 \\
\hline Unmet need for doctors' home visits & 12.8 & 21.7 \\
\hline Unmet need for companionship & 17.5 & 23.0 \\
\hline Sample size & 20,255 & 19,986 \\
\hline
\end{tabular}

${ }^{\mathrm{a}}$ Mean and standard deviation (in parentheses), ADL: Activities of daily living.

The average number of children had dropped from 4.0 in 2000 to 3.2 in 2010 . Since the lower age limit of the survey is 60 years old, the youngest members of those surveyed in 2000 would have been 40 in 1980, when the one-child-policy started to be enforced, and the impact would be minimal. In contrast, some of the older adults interviewed in 2010 were in their 30s in 1980 and could be impacted by the policy. Therefore, the reduction in the number of children could be substantial. There was a marked increase in the percentage of older adults living alone or with spouse only (from $38.4 \%$ to $53.8 \%$ ) and correspondingly a decrease in the percentage of living with children (from $55.5 \%$ to $40.4 \%$ ). However, the proportion of older adults who did not worry about children being unfilial went up, suggesting stronger ties between generations.

The increasing coverage of pensions and other public sources of income was evident between 2000 and 2010. Whereas only half of the older adult population received any income from public sources in 2000, about three-quarters did so in 2010. Correspondingly, the percentage of not worrying about income increased from $56.2 \%$ to $61.4 \%$. The improvement 
in receiving medical care coverage was more significant: Increased from $63.3 \%$ to $95.7 \%$, though the change in the percentage of not worrying about medical care was less impressive: From $46.8 \%$ to $49.9 \%$.

As shown in Table 1, there was a substantial increase in the unmet needs of all the four types of services included in this study. Data suggest (not shown) that there were growing demands for all the services in the same decade, even though there was greater availability of these services except for a slight decrease in doctor's home visit.

Among the control variables, what is worth noting is that the educational profile of Chinese older adults was improving. The share of illiterate older adults declined from $43.1 \%$ in 2000 to $29.0 \%$ in 2010, whereas the shares of those educated went up. Home ownership within the same decade had grown from $53.1 \%$ to $72.5 \%$ for the older adult population.

\subsection{Regression Analysis of Worry about Eldercare}

Table 2 shows the results of logistic regression of having any worry about eldercare in 2000. In Model 1, all three measures of family relations are highly significant. An additional child is associated with a nearly $10 \%$ reduction in the

Table 2. Odds ratios of logistic regression of worry about eldercare, $2000(n=20,255)$.

\begin{tabular}{|c|c|c|c|}
\hline Variable & Model 1 & Model 2 & Model 3 \\
\hline Age & $0.988 * * *$ & 1.007 & 1.007 \\
\hline \multicolumn{4}{|l|}{ Sex } \\
\hline Male & $1.124 * *$ & 1.043 & 1.043 \\
\hline \multicolumn{4}{|l|}{ Female (ref.) } \\
\hline \multicolumn{4}{|l|}{ Residence } \\
\hline Urban & $1.274 * * *$ & 0.986 & 1.023 \\
\hline \multicolumn{4}{|l|}{ Rural (ref.) } \\
\hline \multicolumn{4}{|l|}{ Marital status } \\
\hline Married & $0.754 * * *$ & $0.729 * * *$ & $0.732 * * *$ \\
\hline \multicolumn{4}{|l|}{ Currently not married (ref.) } \\
\hline \multicolumn{4}{|l|}{ Education } \\
\hline \multicolumn{4}{|l|}{ Illiterate (ref.) } \\
\hline Elementary & $0.902 *$ & 0.976 & 0.976 \\
\hline Middle school or higher & 0.947 & $1.297 * * *$ & $1.292 * * *$ \\
\hline ADL difficulty & $1.470 * * *$ & $1.234 * * *$ & $1.227 * * *$ \\
\hline Home ownership & $1.129 * *$ & $1.115^{*}$ & $1.117^{*}$ \\
\hline Number of children & $0.909 * * *$ & $0.916^{* * *}$ & $0.914 * * *$ \\
\hline \multicolumn{4}{|l|}{ Living arrangements } \\
\hline \multicolumn{4}{|l|}{ Alone or with spouse only (ref.) } \\
\hline With children & $0.770 * * *$ & $0.732 * * *$ & $0.732 * * *$ \\
\hline Other & 1.041 & 1.022 & 1.024 \\
\hline No worry about children's filiality & $0.056^{* * *}$ & $0.112 * * *$ & $0.112 * * *$ \\
\hline Receiving any public income & & 1.051 & 1.050 \\
\hline Receiving medical care coverage & & 0.979 & 0.976 \\
\hline No worry about income & & $0.367 * * *$ & $0.368^{* * *}$ \\
\hline No worry about medical care & & $0.174 * * *$ & $0.175^{* * *}$ \\
\hline Unmet need for housework work & & & 0.966 \\
\hline Unmet need for personal care & & & 1.041 \\
\hline Unmet need for doctors' home visits & & & $1.178^{*}$ \\
\hline Unmet need for companionship & & & $1.135^{*}$ \\
\hline
\end{tabular}

${ }^{*} P<0.01,{ }^{*} P<0.01, * * * P<0.001$ for Wald Chi-square test. ADL: Activities of daily living. 
odds of worry about eldercare. Similarly, living with at least a child reduces $23 \%$ of the odds of worry about eldercare. The subjective measure of family relations, worry about children's filiality, is also highly significant. Those who had no worry about children's filiality were only $5 \%$ as likely as those who had such a concern to worry about eldercare.

In Model 2, when older adults' socio-economic resource variables are added, the effects of the three family relations variables remain robust. Although the two objective measures of receiving public income and medical care coverage were not significant, the two subjective measures were highly significant. Those who had no worry about income were only $37 \%$ as likely as those who had such a concern to worry about eldercare, and those who had no worry about medical care coverage were only $18 \%$ as likely as those who had such a concern to worry about eldercare. In Model 3, of the four types of community services, having unmet need for doctors' home visits and unmet need for companionship is associated with higher odds of worry about eldercare, while the effects of family relation variables and older adults' socioeconomic resource variables remained virtually unchanged.

Table 3 shows similar results for 2010. All three family relation variables remain highly significant even when all other variables are controlled for. Older adults' socio-economic resource variables are significant, as well. Among the

Table 3. Odds ratios of logistic regression of worry about eldercare, $2010(n=19,986)$.

\begin{tabular}{|c|c|c|c|}
\hline Variable & Model 1 & Model 2 & Model 3 \\
\hline Age & $0.977 * * *$ & 1.000 & 1.000 \\
\hline \multicolumn{4}{|l|}{ Sex } \\
\hline Male & $1.148 * * *$ & $1.138^{*}$ & $1.133 * *$ \\
\hline \multicolumn{4}{|l|}{ Female (ref.) } \\
\hline \multicolumn{4}{|l|}{ Residence } \\
\hline Urban & 0.947 & 1.058 & $1.140^{*}$ \\
\hline \multicolumn{4}{|l|}{ Rural (ref.) } \\
\hline \multicolumn{4}{|l|}{ Marital status } \\
\hline Married & $0.730 * * *$ & $0.757 * * *$ & $0.759 * * *$ \\
\hline \multicolumn{4}{|l|}{ Currently not married (ref.) } \\
\hline \multicolumn{4}{|l|}{ Education } \\
\hline \multicolumn{4}{|l|}{ Illiterate (ref.) } \\
\hline Elementary & $0.907 *$ & 1.003 & 1.017 \\
\hline Middle school or higher & $0.767 * * *$ & $1.219^{* *}$ & $1.236 * * *$ \\
\hline ADL difficulty & $1.514 * * *$ & $1.153^{* *}$ & $1.137 *$ \\
\hline Home ownership & 1.035 & 1.044 & 1.039 \\
\hline Number of children & $0.888 * * *$ & $0.873 * * *$ & $0.872 * * *$ \\
\hline \multicolumn{4}{|l|}{ Living arrangements } \\
\hline \multicolumn{4}{|l|}{ Alone or with spouse only (ref.) } \\
\hline With children & $0.850 * * *$ & $0.813 * * *$ & $0.813 * * *$ \\
\hline Other & 0.941 & 1.000 & 0.998 \\
\hline No worry about children's filiality & $0.048 * * *$ & $0.104 * * *$ & $0.105 * * *$ \\
\hline Receiving any public income & & $1.184 * * *$ & $1.181^{* * *}$ \\
\hline Receiving medical care coverage & & 1.040 & 1.030 \\
\hline No worry about income & & $0.362 * * *$ & $0.365^{* * *}$ \\
\hline No worry about medical care & & $0.129 * * *$ & $0.128 * * *$ \\
\hline Unmet need for housework work & & & $1.208^{* *}$ \\
\hline Unmet need for personal care & & & 1.075 \\
\hline Unmet need for doctors' home visits & & & 1.033 \\
\hline Unmet need for companionship & & & 1.092 \\
\hline
\end{tabular}

${ }^{*} P<0.01, * * P<0.01, * * * P<0.001$ for Wald Chi-square test. ADL: Activities of daily living. 
community service variables, having unmet need for housework service is associated with higher odds of worry about eldercare.

Among the control variables, older adults who were married and those with less ADL difficulty were less likely to worry about eldercare than their counterparts.

\section{Discussion}

In light of drastic changes in family structure and rapid socio-economic development in China, this study used data from a national survey to explore the presence of worry about eldercare among Chinese older adults between 2000 and 2010. Within one decade, living separately from children had become the way of life for the majority of Chinese older adults. On the other hand, the socio-economic conditions of older adults have been improving, with more covered by pensions and medical care programs, thus, resulting in less worry about income and seeking medical care. Furthermore, the availability of community services is on the rise. In the end, a little surprisingly, worry about eldercare among Chinese older adults remained virtually unchanged during that decade, which could be a result of the competing effects of the two tracks of changes aforementioned.

Our results clearly support Hypothesis 1 regarding the association between socio-economic conditions of older adults and worry about eldercare. Those older adults who did not worry about their income or medical care coverage showed significantly less worry about eldercare. Furthermore, those who lived in communities where available services could meet their particular needs of daily living tended to have less worry about eldercare. These findings are consistent with the health-care utilization model developed by Anderson and others (Andersen and Newman, 2005), where enabling conditions are a set of critical factors that determine individuals' access to health care. They include family resources such as income, health care coverage, and other financial sources. In addition, the amount of health facilities and personnel in a community is another dimension of enabling conditions. These also correspond to the affordability (ability to pay) and availability (of services) factors within the framework of accessibility to health-care developed by Levesque, Harris, and Russell (2013). Zhu (2015) found that, among Chinese oldest old, those who were economically independent and had family members as the primary caregiver were less likely to experience long-term care unmet needs, which we assume to be related to reduce worry about eldercare. Therefore, access to more resources and the provision of community services do alleviate the concern of older adults about eldercare.

Meanwhile, between the two competing hypotheses regarding the effect of family relations when older adults' socioeconomic resources and the provision of community services are taken into account, Hypothesis $2 \mathrm{~b}$ is supported, which predicts that family relations are still important and relevant. It is confirmed by the fact that the number of adult children of older adults, older adults' living arrangements, and their children's filial piety are highly significant in both 2000 and 2010. This finding confirms the prominent role of the family in providing eldercare in many Asian societies, including China. Having more children, living with at least one adult child, and children's filial piety all provide higher possibility and security for older adults to receive care from them. As discussed by Knodel and other scholars (Asis, Domingo, Knodel et al., 1996; Knodel, 2012), receiving care from children is valued highly among many Asian older adults. It serves not only a practical function but also as a symbol of children's affection and the appreciation of the traditional value of filial piety. This finding suggests that family relations remain a crucial element of the equation when older adults assess their prospect of receiving eldercare.

China's population aging happens at a time of rapid urbanization and industrialization, which have weakened the functions of traditional family support (Jackson, 2010). The traditional mode of family care faces serious challenges. Longer life expectancy comes with a rapidly growing older adult population and more non-communicable, chronic diseases, which are related to functional impairments and disability. The demographic reality makes it impossible for all older adults to live with their adult children. More older adults live alone or with their spouse only. All these points to a pressing dilemma: On the one hand, there is an ever-growing demand for care and services to older adults; on the other hand, individual families, the traditional care providers, are increasingly incapable of fulfilling their functions. Therefore, the role of the public sector, including state welfare programs and community services, becomes increasingly prominent in dealing with these challenges by providing income security, medical care, and social services.

Against such a backdrop, the results show some positive development for Chinese older adults. Overall, the personal and economic circumstances of Chinese older adults have been improving. The results show that during the first decade of this century, Chinese older adults became more educated, enjoyed higher home ownership, received more pension or other public income, and more medical care coverage. These changes certainly reduce older adults' worry about eldercare.

In addition, more and more people have recognized the necessity of getting support from the community to complement the provision of eldercare fulfilled by individual families ( $\mathrm{Du}, 2013)$. Similar trends are seen in other Asian Countries as 
well. Japan and South Korea, two leading industrialized countries coupled with rapid population aging, have witnessed a significant expansion of both public and market provisions of eldercare since the 1990s. Care burdens traditionally assumed by women in these societies are gradually shifted to the market and community (Peng, 2012). There has been discussion in China about the distinction between family care - the traditional practice where eldercare is entirely given by family members - and at-home care - where older adults use financial resources to acquire daily care and services from the community or neighborhood. The latter is considered a social eldercare model (Chen, 2002). Eldercare, which has been mainly limited to the family as the sole care provider, is gradually giving way in China to a shared responsibility of the family, state, and market. Boundaries are crossed between informal and formal, public and private sectors (Zhang and Yeung, 2012). As a result, more community services emerge in both urban and rural neighborhoods, such as household work, health care at home, companionship, and meal services. Although the development of these services is still at its early stage, the results show that the services that meet older adults' needs do reduce their worry about eldercare (Zhang, 2002). In the future, not only are more services in demand but also will be the kinds of services that suit local circumstances and satisfy the real needs of the elderly residents (Zhang, 2002).

The support of the first hypothesis seems to suggest that the constraints faced by older adults, such as smaller family size and less chance of living with adult children, can be compensated by their improving resources at disposal and greater presence of community services resulted from the ongoing socio-economic development. Some believe that in the process of modernization, the social model will ultimately replace the family eldercare model and become the dominant form of care (Chen, 2002). Our analysis, however, points to a different direction. Family ties between generations still matter to older adults. The finding that while fewer older adults were living with their adult children, the percentage of older adults not worrying about their children's filiality went up instead of going down during the same decade suggests that family bond remains strong China. The higher percentage of older adults living alone cannot be simply interpreted as evidence of the erosion of traditional values. Independent living of older adults is transitory in nature, which is one phase of the eldercare process. It has been found that Chinese older adults would like to live independently in their family as long as their health permits (Gu, Dupre, and Liu, 2007). Coresidence is still the ideal living arrangement when older adults' health deteriorates and need for daily assistance arises. This has been found in Taiwan, the Philippines, Thailand, and Singapore as well (Asis, Domingo, Knodel et al., 1996). Moreover, as discussed earlier, the prominent role of coresidence in Asian societies may not only lie in its practical function of providing eldercare but also in its compliance with traditional practice, which is viewed as an expression of filial piety.

This study has its limitations. First, since the survey from the two-time points does not follow the same cohort, it prevents a life course analysis of changes with age, such as the living arrangements and worry about eldercare, which would be more revealing about the dynamics of their relationship. Second, this study also has measurement shortcomings. The measurement of unmet need may not be accurate because the need for some older adults may not be met even if the community services are available. Other aspects, such as the quality of services, maybe at work as well. In addition, some of the variables on income and medical care coverage are still crude measures. For example, while the percentage of receiving health-care coverage increased from $63.3 \%$ in 2000 to $95.7 \%$ in 2010 , the change in the percentage of not worrying about medical care was much less impressive: Only from $46.8 \%$ to $49.9 \%$. This may reflect the disparity in benefit coverage among older adults between regions and urban/rural areas. There is also a wide variation in the cost of living. We attempted to address this by including subjective measures on worry about income or medical care in the paper. Third, since the development of community services for older adults is only at its early stage in China, the availability and usage of some types of services are still uncommon. Their full impacts remain to be seen. As reported earlier, we did find a distinction between the availability and unmet needs of certain services. It would be interesting to do a more in-depth analysis on this subject, which is beyond the scope of this paper.

Despite these shortcomings, the findings of this study clearly show that the family is still the ideal institution for eldercare in China, even as it has undergone profound socio-economic transformations. As the state increases investment in welfare programs to improve older adults' financial and medical care coverage and to provide more community services, what shall not be overlooked is polices that strengthen family ties between generations. It is unrealistic and counterproductive to expect to replace family eldercare with formal services. The value of filial piety and the responsibilities it entails should be upheld and encouraged (Chow, 2004). Measures should be taken to enable and facilitate increasingly shrinking and dispersed families to engage in eldercare in varying forms and shapes (Chan, 2005). Formal services should serve to crowd in, rather than crowd out, traditional family support (World Bank, 1994).

\section{Acknowledgments}

The authors would like to thank the two reviewers for their helpful comments. 


\section{Authors' Contribution}

R Sun designed the study, performed part of the analysis, drafted and revised the manuscript. H Wang participated in data collection and preparation, performed part of the analysis, interpreted the results, and revised the manuscript.

\section{Conflicts of Interest}

No conflicts of interest have been reported by the authors.

\section{Ethics Approval}

No ethics approval was required for this study. The datasets were obtained from China Research Center on Aging, which are publicly accessible on request.

\section{Funding}

The authors declare that they have no financial support for this study.

\section{Disclaimer}

Views expressed in this article are solely those of the authors and do not necessarily reflect those of the Cleveland State University or China Research Center on Aging.

\section{References}

Andersen R and Newman JF. (2005). Societal and Individual Determinants of Medical Care Utilization in the United States. Milbank Quarterly, 83(4):515-21. https://dx.doi.org/10.1111/j.1468-0009.2005.00428.x

Asis MMB, Domingo L and Knodel J, et al. (1995). Living Arrangements in Four Asian Countries: A Comparative Perspective. Journal of Cross-Cultural Gerontology, 10(1-2):145-62. https://dx.doi.org/10.1007/BF00972034.

Cai Y. (2013). China's New Demographic Reality: Learning from the 2010 Census. Population and Development Review, 39(3):37196. https://dx.doi.org/10.1111/j.1728-4457.2013.00608.x.

Chan A, Biddlecom AE and Ofstedal MB, et al. (2003). The Relationship between Formal and Familial Support of the Elderly in Singapore and Taiwan. Asian Metacenter Research Paper Series, No. 9. National University of Singapore.

Chan A. (2005). Aging in Southeast and East Asia: Issues and Policy Directions. Journal of Cross-Cultural Gerontology, 20(4):269-84. https://dx.doi.org/10.1007/s10823-006-9006-2.

Chen S. (2002). Summary of Studies on Eldercare Models in Contemporary China. Chinese Sociology and Anthropology, 34(2):24-42. https://dx.doi.org/10.2753/CSA0009-4625340224.

Cheng S and Chan ACM. (2006). Filial Piety and Psychological Well-Being in Well Older Chinese. Journal of Gerontology, 61B(5):P262-9. https://dx.doi.org/10.1093/geronb/61.5.p262.

Chow N. (2004). Asian Value and Aged Care. Geriatrics and Gerontology International, 4:S21-5. https://dx.doi.org/10.1111/j.14470594.2004.00139.x.

Cowgill DQ and Holmes LD. (1972). Aging and Modernization. New York: Appleton-Century-Crofits.

Du P. (2013). Intergenerational Solidarity and Old-Age Support for the Social Inclusion of Elders in Mainland China: the Changing Roles of Family and Government. Ageing and Society, 33(1):4-63. https://dx.doi.org/10.1017/S0144686X12000773.

Feng Z, Liu C and Guan X, et al. (2012). China's Rapidly Aging Population Creates Policy Challenges in Shaping a Viable Long-Term Care System. Health Affairs, 31(12):2764-73. https://dx.doi.org/10.1377/hlthaff.2012.0535.

Fernandez-Carro C. (2016). Ageing at Home, Co-Residence or Institutionalization? Preferred Care and Residential Arrangements of Older Adults in Spain. Ageing and Society, 36(3):586-612. https://dx.doi.org/10.1017/S0144686X1400138X.

Gu D, Dupre ME and Liu G. (2007). Characteristics of the Institutionalized and Community-Esiding Oldest-Old in China. Social Science and Medicine, 64(4):871-83. https://dx.doi.org/10.1016/j.socscimed.2006.10.026.

Hayashi M. (2011). The Care of Older People in Japan: Myths and Realities of Family Care. History and Policy. Available from: http:// www.historyandpolicy.org/policy-papers/papers/the-care-of-older-people-in-japan-myths-and-realities-of-family-care. [Last 
accessed on 2019 Jul 12].

Hu Z and Peng X. (2015). Household Changes in Contemporary China: An Analysis Based on the four Recent Censuses. The Journal of Chinese Sociology, 2(1):9. https://dx.doi.org/10.1186/s40711-015-0011-0.

Jackson R. (2010). The Aging of China. Center for Strategic and International Studies. Critical Questions. Available from: http://www. csis.org/publication/aging-china. [Last accessed on 2019 Jul 12].

Jiang Q and Liu Y. (2016). Low Fertility and Concurrent Birth Control Policy in China. Journal of the History of the Family, 21(4):55177. https://dx.doi.org/10.1080/1081602X.2016.1213179.

Kawakami A and Son J. (2015). "I Don’t Want to be a Burden": Japanese Immigrant Acculturation and Their Attitudes Toward NonFamily-Based Eldercare. Ageing International, 40(3):262-76. https://dx.doi.org/10.1007/s12126-015-9220-8.

Knodel J and Chayovan N. (2012). Inter-Generational Family Care for and by Older People in Thailand. International Journal of Sociology and Social Policy, 32(11/12):682-94. https://dx.doi.org/10.1108/01443331211280719.

Knodel J. (2012). The Future of Family Support for Thai Elderly: Views of the Populace. Population Studies Center Research Report 12-779. Michigan: University of Michigan. Available from: https://www.psc.isr.umich.edu/pubs/abs/7754. [Last accessed on 2019 Jul 12].

Lee M, Lin H and Chang M. (1995). Living Arrangements of the Elderly in Taiwan: Qualitative Evidence. Journal of Cross-Cultural Gerontology, 10(1-2):53-78. https://dx.doi.org/10.1007/BF00972031.

Lee W and Kwok H. (2006). Aging and Eldercare in China: The Case of Guangzhou. Social Development Issues, 28(1):20-33.

Leung JCB. (2010). Residential Care Services for Older People in China: From State to Market Provisions? Social Development Issues, 32(1):31-47. Available from: https://www.ingentaconnect.com/contentone/icsd/sdi/2010/00000032/00000001/art00003. [Last accessed on 2019 Jul 12].

Levesque JF, Harris MF and Russell G. (2013). Patient-Centered Access to Health Care: Conceptualising Access at the Interface of Health Systems and Populations. International Journal for Equity in Health, 12:18. https://dx.doi.org/10.1186/1475-9276-12-18.

Lin W. (2017). The Development of Community-Based Service for Older People in Urban China: A Case Study in Guangzhou City. International Social Work, 60(6):1606-18. https://dx.doi.org/10.1177/0020872816631597.

Liu H, Han X and Xiao Q, et al. (2015). Family Structure and Quality of Life of Elders in Rural China: The Role of the New Rural Social Pension. Journal of Aging and Social Policy, 27(2):123-38. https://dx.doi.org/10.1080/08959420.2014.977662.

Mehta K, Osman MM and Alexander EY. (1995). Living Arrangements of the Elderly in Singapore: Cultural Norms in Transition. Journal of Cross-Cultural Gerontology, 10(1-2):53-78. https://dx.doi.org/10.1007/BF00972033.

Meng X and Luo C. (2008). What Determines Living Arrangements of the Elderly in URBAN CHINA? In: Gustafsson BA, Li S and Sicular T, editors. Inequality and Public Policy in China. Cambridge: Cambridge University Press. p267-86.

Ng AC, Phillips DR and Lee WK. (2002). Persistence and Challenges to Filial Piety and Informal Support of Older Persons in a Modern Chinese Society: A Case Study in Tuen Mun, Hong Kong. Journal of Aging Studies, 16(2):135-53. https://dx.doi.org/10.1016/ S0890-4065(02)00040-3.

Peng I. (2012). Social and Political Economy of Care in Japan and South Korea. International Journal of Sociology and Social Policy, 32(11/12):636-49. https://dx.doi.org/10.1108/01443331211280683.

Shen Y and Yeatts DE. (2013). Social Support and Life Satisfaction Among Older Adults in China: Family-Based Support Versus Community Based Support. International Journal of Aging and Human Development, 77(3):189-209. https://dx.doi.org/10.2190/ AG.77.3.b.

United Nations, Department of Economic and Social Affairs, Population Division (2019). World Population Prospects 2019: Highlights (ST/ESA/SER.A/423). Available from: https://www.reliefweb.int/sites/reliefweb.int/files/resources/WPP2019_Highlights.pdf. [Last accessed on 2019 Jul 12].

Wang J, Chen T and Han B. (2014). Does Co-Residence with Adult Children Associate with Better Psychological Well-Being Among the Oldest Old in China? Aging and Mental Health, 18(2):232-39. https://dx.doi.org/10.1080/13607863.2013.837143.

Whyte MK. (2003). China's Revolutions and Intergenerational Relations. Ann Arbor: University of Michigan Center for Chinese Studies. Available from: https://www.scholar.harvard.edu/martinwhyte/publications/chinas-revolutions-and-intergenerational- 
relations-and-persistence-family-o. [Last accessed on 2019 Jul 12].

World Bank. (1994) Averting the Old Age Crisis: Policies to Protect the old and Promote Growth. New York: World Bank. Available from: http://documents.worldbank.org/curated/en/973571468174557899/Averting-the-old-age-crisis-policies-to-protect-the-oldand-promote-growth. [Last accessed on 2019 Jul 12].

Wu X and Luo X. (2013). Healthy Aging as the Core Concept of the Medical and Health Services for the Elderly. In Wu Y and Dang J, editors. China Report of the Development on Aging Cause. Beijing, China: Social Sciences Academic Press. p94-116.

Xu Q and Chou JC. (2011). Exploring the Community-Based Service Delivery Model: Elderly Care in China. International Social Work, 54(3):374-87. https://dx.doi.org/10.1177/0020872810396260.

Yang X. (2013). Breakthrough in China's System of Security for the Elderly.” In Wu Y and Dang J, editors. China Report of the Development on Aging Cause. Beijing, China: Social Sciences Academic Press. p73-93.

Zavoretti R. (2006). Family-Based Care for China's Ageing Population. Asia Europe Journal, 4:211-28. https://dx.doi.org/10.1007/ s10308-006-0060-8.

Zeng Y and Wang Z. (2003). Dynamics of Family and Elderly Living Arrangements in China: New Lessons Learned from the 2000 Census. China Review, 3(2):95-119.

Zhang A, Nikoloski Z and Mossialos E. (2017). Does Health Insurance Reduce Out-of-pocket Expenditure? Heterogeneity Among China's Middle-Aged and Elderly. Social Science and Medicine, 190(1):11-9. https://dx.doi.org/10.1016/j.socscimed.2017.08.005.

Zhang J. (2017). China Raises Pensions amid Pressure from Slowing Economy, Aging Population. Accessible at CCTV News. Available from: http://www.english.cctv.com/2017/04/14/ARTI36vi4XpvJPQME0QE2RbO170414.shtml. [Last accessed on 2019 Jul 12].

Zhang W. (2002). China's Strategic Options for Solving the Problems of Aging in the Twenty-First Century. Chinese Sociology and Anthropology, 34(1):69-74.

Zhang Y and Yeung WJ. (2012). Shifting Boundaries of Care in Asia: An Introduction. International Journal of Sociology and Social Policy, 32(11/12):612-22. https://dx.doi.org/10.1108/01443331211280665.

Zhang Y, Yeager VA and Hou S. (2016). The Impact of Community-Based Supports and Services on Quality of Life Among the Elderly in China: A Longitudinal Study. Journal of Applied Gerontology. https://dx.doi.org/10.1177\%2F0733464816661945.

Zhu H. (2015). Unmet Needs in Long-Term Care and their Associated Factors Among the Oldest Old in China. BMC Geriatrics, 15(46):1-11. https://dx.doi.org/10.1186/s12877-015-0045-9. 